\title{
GAMBARAN SELF CARE BEHAVIOUR PADA PASIEN HIPERTENSI DI PUSKESMAS WILAYAH KOTA DENPASAR
}

\author{
Meril Valentine Manangkot ${ }^{1}$, I Made Suindrayasa ${ }^{2}$ \\ ${ }^{1,2}$ Dosen Program Studi Sarjana Keperawatan dan Profesi Ners Fakultas Kedokteran Universitas Udayana \\ Alamat Korespondensi: merilvalentine@unud.ac.id
}

\begin{abstract}
Abstrak
Hipertensi merupakan penyakit kronis dan sering disebut silent killer karena tidak disertai dengan gejala yang khas sebelum memasuki fase komplikasi. Hipertensi dapat dibedakan menjadi dua yaitu hipertensi primer dan hipertensi sekunder. Tingginya jumlah pasien hipertensi saat ini memerlukan komitmen dalam upaya penatalaksanaan penyakit hipertensi berkelanjutan. Salah satunya dengan membangun self care behaviour yang adekuat pada pasien. Penelitian ini bertujuan untuk mengidentifikasi gambaran self care behaviour pada pasien hipertensi di Puskesmas wilayah Kota Denpasar. Responden dalam penelitian ini adalah 115 pasien hipertensi. Pengumpulan data menggunakan kuesioner dengan teknik consecutive sampling. Analisis data univariat digambarkan dalam bentuk distribusi frekuensi dan tendensi sentral. Hasil penelitian menunjukkan rata-rata skor self care behaviour adalah 20,30, dengan skor tertinggi adalah 28, dan skor terendah adalah 10.
\end{abstract}

Kata kunci: hipertensi, komplikasi, self care behaviour

\begin{abstract}
Hypertension is a chronic disease. Hypertension can be divided into two, namely primary hypertension and secondary hypertension. The high incidence of hypertension currently requires commitment in the management of sustainable hypertension. One of them is developing adequate self care behaviour. This study aimed to identify the description of self care behaviour in hypertension patients in Denpasar. Respondents were 115 hypertension patients in 3 community health centers in Denpasar. Data collected using questionnaire with consecutive sampling technique. Univariate data analysis is described with frequency distribution and central tendency. The results showed that the average score of self care behaviour was 20.30, with the highest score was 28 , and the lowest score was 10 .
\end{abstract}

Keywords: hypertension, complication, self care behaviour

\section{PENDAHULUAN}

Hipertensi adalah suatu keadaan dimana tekanan darah sistolik menunjukkan hasil >140 $\mathrm{mmHg}$ dan tekanan darah diastolik menunjukkan hasil $>90$ mmHg (Smeltzer \& Bare, 2011). Hipertensi sering disebut sebagai "silent killer". Sebagian besar pasien dengan hipertensi tidak menyadari karena tidak disertai dengan gejala yang khas sebelum memasuki fase komplikasi. Gejala yang seringkali muncul, antara lain sakit kepala di pagi hari, mimisan, perubahan irama jantung menjadi tidak teratur, perubahan penglihatan, dan telinga berdengung. Hipertensi berat dapat menyebabkan kelelahan, mual, muntah, kecemasan, nyeri dada, dan tremor (WHO, 2019).

Berdasarkan etiologinya, hipertensi dapat dibedakan menjadi dua yaitu hipertensi primer dan hipertensi sekunder. Hipertensi primer merupakan hipertensi yang terjadi tanpa penyakit medis yang mendasari. Hipertensi sekunder merupakan hipertensi yang diakibatkan oleh penyakit atau obat-obatan tertentu. Kejadiannya kurang dari $10 \%$ dari total 
kasus hipertensi (Direktorat Bina Farmasi Komunitas dan Klinik Depkes RI, 2006).

Prevalensi hipertensi di dunia bervariasi. WHO mencatat wilayah Afrika memiliki prevalensi hipertensi tertinggi (27\%) sedangkan Amerika memiliki prevalensi hipertensi terendah (18\%). Keadaan saat ini menunjukkan bahwa jumlah orang dewasa dengan hipertensi meningkat dari 594 juta pada tahun 1975 menjadi 1,13 miliar pada tahun 2015, dimana peningkatan tersebut sebagian besar terlihat di negara-negara berpenghasilan rendah dan menengah. Peningkatan tersebut utamanya disebabkan oleh peningkatan faktor risiko hipertensi pada populasi tersebut (WHO, 2019).

Menurut World Health Organization tahun 2010, komplikasi hipertensi telah menyebabkan 9,4 juta kematian tiap tahun di seluruh dunia, $45 \%$ karena penyakit jantung dan $51 \%$ lainnya karena penyakit stroke (Kemenkes RI, 2013). Prevalensi kasus penyakit hipertensi di Bali terbilang terus mengalami peningkatan. Bahkan hipertensi masih menjadi tiga besar dalam daftar 10 pola penyakit tidak menular (PTM) di Bali yang dihimpun oleh Dinas Kesehatan Provinsi Bali (NV, 2018). Prevalensi kasus hipertensi di Bali pada tahun 2017 sebanyak 132.444 kasus, dimana 7.237 kasus berada di wilayah Kota Denpasar (Dinkes Provinsi Bali, 2018).

Tingginya jumlah pasien dengan hipertensi dan beratnya potensi komplikasi hipertensi memerlukan komitmen dalam upaya penatalaksanaan penyakit hipertensi. Sebagai salah satu penyakit kronis, perawatan pasien dengan hipertensi bersifat berkelanjutan baik secara farmakologis maupun nonfarmakologis (Smeltzer \& Bare, 2011). Oleh sebab itu diperlukan perilaku kesehatan yang adekuat, yang dapat disebut sebagai self care behaviour. Self care behaviour optimal merupakan salah satu komponen mencapai keberhasilan pengobatan pasien hipertensi. Penelitian ini bertujuan untuk mengidentifikasi gambaran self care behaviour pada pasien hipertensi di Puskesmas wilayah Kota Denpasar.

\section{METODE PENELITIAN}

Penelitian ini merupakan penelitian non-eksperimental. Rancangan penelitian adalah deskriptif dengan pendekatan cross sectional. Populasi penelitian adalah pasien hipertensi di wilayah kerja Puskesmas Kota Denpasar, meliputi Puskesmas I Denpasar Timur, Puskesmas II Denpasar Barat, dan Puskesmas III Denpasar Utara. Teknik sampling yang digunakan adalah consecutive sampling. Sampel berjumlah 115 orang.

Variabel yang diidentifikasi dalam penelitian ini adalah self care behaviour. Pengumpulan data menggunakan kuesioner self care behaviour, yang terdiri dari 14 pernyataan, dengan pilihan jawaban "tidak pernah" (skor 0), "kadangkadang" (skor 1), dan "selalu” (skor 2). Data kemudian dianalisis menggunakan analisis univariat meliputi data karakteristik responden (usia, jenis kelamin, tingkat pendidikan) dan data variabel self care behaviour. Data karakteristik responden ditampilkan dalam bentuk tabel distribusi frekuensi, sedangkan data self care behaviour ditampilkan dalam bentuk tendensi sentral.

\section{HASIL PENELITIAN}

Hasil penelitian mengenai karakteristik responden ditampilkan pada Tabel 1, sedangkan data usia dan self care behaviour ditampilkan pada Tabel 2 . 
Tabel 1. Karakteristik Responden berdasarkan Jenis Kelamin dan Tingkat Pendidikan

\begin{tabular}{ccc}
\hline \multicolumn{1}{c}{ Variabel } & Frekuensi (n) & Persentase (\%) \\
\hline Jenis Kelamin & & \\
Laki-laki & 51 & 44,3 \\
Perempuan & 64 & 55,7 \\
\hline Total & $\mathbf{1 1 5}$ & $\mathbf{1 0 0 , 0}$ \\
\hline Tingkat Pendidikan & & 7,0 \\
Tidak Sekolah & 8 & 15,7 \\
SD & 18 & 29,6 \\
SMP & 34 & 29,6 \\
SMA & 34 & 18,3 \\
Perguruan Tinggi & 21 & $\mathbf{1 0 0 , 0}$ \\
\hline Total & $\mathbf{1 1 5}$ &
\end{tabular}

Tabel 2. Gambaran Usia dan Skor Self Care Behaviour

\begin{tabular}{|c|c|c|}
\hline Variabel & Mean \pm SD & Min-Max \\
\hline Usia (tahun) & $62,33 \pm 8,412$ & $39-76$ \\
\hline Self Care Behaviour & $20,30 \pm 3,958$ & $10-28$ \\
\hline
\end{tabular}

Hasil penelitian didapatkan bahwa berdasarkan distribusi jenis kelamin responden, mayoritas adalah perempuan sebanyak 64 orang $(55,7 \%)$ dan pendidikan terakhir responden mayoritas adalah SMP dan SMA sebanyak masing-masing 34 orang $(29,6 \%)$. Hasil penelitian ini juga menemukan bahwa rata-rata responden berada pada usia 62,33 tahun, dengan

\section{PEMBAHASAN}

Berdasarkan hasil penelitian ini, rata-rata usia responden berada pada usia 62,33 tahun, dimana usia ini dapat dikategorikan sebagai kategori lansia. Banyak lansia yang mengalami hipertensi karena perubahan fisiologis tubuh akibat proses menua. Salah satu masalah kesehatan yang sering terjadi seiring dengan peningkatan usia adalah hipertensi. Hal ini disebabkan karena adanya perubahan struktur pembuluh darah sehingga diameter pembuluh darah menjadi lebih sempit dan dinding pembuluh darah menjadi kurang elastis. Selain itu, penurunan elastisitas usia termuda yaitu 39 tahun dan usia tertua yaitu 76 tahun.

Hasil analisis gambaran self care behaviour menunjukkan rata-rata skor self care behaviour adalah 20,30, dengan skor tertinggi yang berhasil dicapai adalah 28 , dan skor terendah adalah 10 .

pembuluh darah juga terjadi di arteri perifer sehingga menimbulkan resistensi pembuluh darah perifer. Hal inilah yang dapat meningkatkan tekanan darah (Guyton \& Hall, 2007; Depkes RI, 2006).

Perkembangan prahipertensi dapat dimulai pada usia 10-20 tahun (ditandai dengan meningkatnya curah jantung), kemudian hipertensi dini dapat terjadi usia 20-40 tahun (ketika terjadi perubahan tahanan perifer), kemudian menjadi hipertensi pada usia $>40$ tahun (Anggraeni, Waren, Situmorang, Asputra \& Siahaan, 2009).

Hasil penelitian ini juga menunjukkan bahwa sebagian besar 
responden adalah perempuan sebanyak 64 orang $(55,7 \%)$. Hal ini dapat terjadi karena pasien perempuan yang cenderung ditemui di pelayanan kesehatan saat penelitian ini berlangsung. Perempuan cenderung aktif memeriksakan diri ke pelayanan kesehatan jika mengalami gangguan kesehatan. Hal ini sesuai dengan penelitian Logen \& Balqis (2015) yang mendapatkan hasil $83,3 \%$ responden perempuan lebih banyak memanfaatkan pelayanan kesehatan dibandingkan dengan responden yang berjenis kelamin laki-laki.

Selain itu, menurut Singalingging (2011) dalam Novitaningtyas (2014), rata-rata perempuan akan mengalami peningkatan risiko hipertensi ketika memasuki periode menopause. Perempuan yang belum menopause dilindungi oleh hormone estrogen yang berperan dalam regulasi kadar High Density Lipoprotein (HDL) dan Low Density Lipoprotein (LDL), yang mempengaruhi aterosklerosis.

Berdasarkan tingkat pendidikan, sebagian besar responden berpendidikan terakhir lulus SMP dan SMA sebanyak masing-masing 34 orang $(29,6 \%)$, lalu disusul dengan lulusan perguruan tinggi sebanyak 21 orang $(18,3 \%)$. Tingkat pendidikan bisa menentukan seseorang dalam menyerap dan memahami informasi / pengetahuan. Secara umum, semakin tinggi pendidikan seseorang maka akan semakin baik pula pengetahuannya (Yusra, 2010).

Seseorang dengan pendidikan yang tinggi dapat lebih matang dalam proses perubahan dirinya sehingga lebih mudah menerima pengaruh luar yang positif, obyektif dan terbuka terhadap berbagai informasi termasuk informasi kesehatan. Tingkat pendidikan juga dapat mempengaruhi kemampuan dan pengetahuan seseorang dalam menerapkan pola hidup sehat (Malikatin, 2020).

Gambaran skor self care behaviour menunjukkan rata-rata skor self care behaviour responden adalah 20,30, dimana terdapat responden yang memiliki skor maksimal mencapai 28. Hal ini menunjukkan sebagian besar responden dalam penelitian ini telah mendapatkan informasi yang adekuat, tidak hanya mengenai penyakit hipertensinya, tetapi juga dengan konsep perawatan terkait penyakitnya. Hasil sejenis didapatkan oleh penelitian Romadhon, Haryanto, Makhfudli, \& Hadisuyatmana (2020), yang mendapatkan hasil dari 252 responden lansia yang diteliti, 73 orang (29\%) berada pada kategori self care behaviour yang baik, dan 99 orang $(39,3 \%)$ berada pada kategori self care behaviour yang cukup.

Hal ini juga sesuai dengan penelitian Salami, Dewi, \& Sajodin (2017) yang mendapatkan hasil self care behaviour lansia hipertensi, kategori baik sebanyak 63\%. Hal ini dapat disebabkan oleh adanya kesadaran yang tinggi pada responden dalam mengelola penyakitnya. Hal ini juga ditandai dengan sebagian besar responden secara rutin memeriksakan tekanan darahnya.

\section{SIMPULAN DAN SARAN}

Hipertensi merupakan salah satu masalah kesehatan yang sering terjadi akibat peningkatan usia. Hasil penelitian mendapatkan sebagian besar responden adalah perempuan $(55,7 \%)$, lulusan SMP dan SMA (29,6\%), berusia rata-rata 62,33 tahun, dan memiliki rerata skor self care behaviour sebesar 20,30.

Gambaran tersebut mencerminkan self care behaviour responden dalam penelitian ini berada 
dalam kategori yang baik. Hal ini merupakan hal yang perlu tetap dipertahankan, bahkan diupayakan untuk menjadi lebih baik lagi. Beberapa hal yang dapat dilakukan antara lain melakukan pembinaan kesehatan dengan melibatkan petugas di pelayanan kesehatan, pasien, serta keluarga untuk bersama-sama aktif dalam mengembangkan manajemen kesehatan diri untuk pasien demi terwujudnya self care behaviour pasien yang adekuat dan peningkatan kualitas hidup pasien.

\section{DAFTAR PUSTAKA}

Anggraeni, A.D., Waren, A., Situmorang, E., Asputra, H., Siahaan, S.S. (2009). FaktorFaktor yang berhubungan dengan Kejadian Hipertensi Pada Pasien yang Berobat di Poliklinik Dewasa Puskesmas Bangkinang. Fakultas Kedokteran, Universitas Riau

Dinas Kesehatan Provinsi Bali. 2018. Profil Kesehatan Provinsi Bali Tahun 2017. (https://diskes.baliprov.go.id/wpcontent/uploads/2019/06/Bali_Pro fil_2017_ds.pdf, diakses tanggal 5 Maret 2020)

Direktorat Bina Farmasi Komunitas dan Klinik Depkes RI. 2006. Pharmaceutical Care untuk Penyakit Hipertensi, (http://www.depkes.go.id/, diakses tanggal 20 Februari 2018)

Depkes RI. (2006). Pedoman Teknis Penemuan dan Tatalaksana Penyakit Hipertensi. Direktorat Pengendalian Penyakit Tidak Menular. Jakarta

Guyton A.C, Hall J.E. (2007). Buku Ajar Fisiologi Kedokteran (edisi 11). Jakarta: EGC.
Kementerian Kesehatan RI. (2013). Pusat Data dan Informasi, Situasi Kesehatan Jantung. Jakarta: Kementerian Kesehatan RI

Logen, Y., \& Balqis, D. (2015). Faktor Yang Berhubungan Dengan Pemanfaatan Pelayanan Kesehatan Oleh Pemulung Di TPA Tamangapa. Skripsi. Universitas Hasanudin.

Novitaningtyas, T. (2014). Hubungan karakteristik (umur, jenis kelamin, tingkat pendidikan) dan aktivitas fisik dengan tekanan darah pada lansia di kelurahan makamhaji kecamatan kartasura kabupaten sukoharjo (Doctoral dissertation, Universitas Muhammadiyah Surakarta).

NV. 2018. Hipertensi 3 Besar Penyakit Masa Kini, (https://www.nusabali.com/index. php/berita/39531/hipertensi-3besar-penyakit-masa-kini, diakses tanggal 21 Februari 2019)

Romadhon, W. A., Haryanto, J., Makhfudli, M., \& Hadisuyatmana, S. (2020). Hubungan antara Self Efficacy dan Self Care Behaviour pada Lansia dengan Hipertensi. Jurnal Penelitian Kesehatan" SUARA FORIKES"(Journal of Health Research" Forikes Voice"), 11(4), 394-397.

Salami, S., Dewi, I. P., \& Sajodin, S. (2017). Implementasi Fungsi Keluarga Dan Self Care Behaviour Lansia Hipertensi Di Wilayah Kerja Puskesmas Cijagra Lama Bandung. Jurnal Keperawatan'Aisyiyah, 4(2), 7985.

Smeltzer, S. C., \& Bare, B.G. (2011). Buku Ajar Keperawatan MedikalBedah Brunner \& Suddarth. Edisi 12. Jakarta: EGC 
Yusra, A. (2010). Hubungan Antara Dukungan Keluarga Dengan Kualitas Hidup Pasien Diabetes Mellitus Tipe 2 di Poliklinik Penyakit Dalam Rumah Skit Umum Pusat Fatmawati Jakarta. Tesis. Depok: Magister Ilmu Keperawatan Kekhususan Keperawatan Medikal Bedah Fakultas Ilmu Keperawatan Universitas Indonesia Depok.

World Health Organization. 2019. Hypertension, (https://www.who.int/newsroom/factsheets/detail/hypertension, diakses tanggal 5 Maret 2020) 